\title{
Um olhar sobre a educação ambiental expressa nas diretrizes curriculares nacionais para a educação ambiental
}

\section{A look on environmental education expressed in national curriculum guidelines for environmental education}

\author{
Taís Conceição dos Santos ${ }^{1}$ \\ Marco Antonio Ferreira da Costa ${ }^{2}$
}

\begin{abstract}
RESUMO
Pela gravidade da situação ambiental em todo o mundo, tornou-se indiscutível a necessidade de se abordar a temática ambiental em todos os níveis escolares para que as novas gerações formem conceitos e, sobretudo, valores e atitudes que integrem o ser humano com o ambiente, possibilitando um processo de transformação do atual quadro ambiental do nosso planeta. Diante deste cenário, este trabalho, se propõe a analisar como a Educação Ambiental é apresentada e sugerida aos docentes e às instituições de ensino, nas Diretrizes Curriculares Nacionais para a Educação Ambiental. O estudo que tratou-se de uma pesquisa documental de cunho descritivo-explicativo dessas diretrizes, apontou como resultados que a Educação Ambiental não se limita à preservação do meio ambiente, mas incorpora os aspectos sociais, econômicos, éticos e políticos além, é claro, de reconhecê-la como em uma temática a ser inserida no currículo de modo diferenciado numa abordagem integral, com o estabelecimento de discussões e análises mais amplas.
\end{abstract}

Palavras-chave: educação ambiental, diretrizes curriculares nacionais, meio ambiente.

\begin{abstract}
Due to the severity of the environmental situation around the world it became the undisputed need to address environmental issues at all educational levels so that new generations form concepts and, above all, values and attitudes that are part of the human with the environment, enabling a process of transformation of the current environmental framework of our planet. Given this scenario, this work proposes to analyze how environmental education is presented and suggested for teachers and educational institutions, the National Curriculum Guidelines for Environmental Education. The study dealt with is a documentary research descriptive-explanatory nature of these guidelines, as results showed that environmental education is not limited to the preservation of the environment, but incorporates the social, economic, ethical and political aspects and, of course, to recognize it as an issue to be included in the curriculum differently in a holistic approach, with the establishment of broader discussions and analyzes.
\end{abstract}

Keywords: environmental education, national curriculum guidelines, environment.

\footnotetext{
1 Doutoranda do Programa de Pós-graduação em Ensino em Biociências e Saúde na FIOCRUZ (IOC/FIOCRUZ) e Professora do Centro Federal de Educação Tecnológica Celso Suckow da Fonseca (CEFET/RJ). e-mail: taisquim@hotmail.com

2 Professor do Programa de pós-graduação em Ensino em Biociências e Saúde IOC/ FIOCRUZ. e-mail: costa@fiocruz.br
} 


\section{INTRODUÇÃO}

A preocupação com a interferência do ser humano no meio ambiente é antiga, apesar de recentemente ter tomado enormes proporções, assumindo uma postura política, social e econômica, fazendo da crise ambiental a crise do nosso tempo (LEFF, 2002). Já em 1864, George Perkin Marsh previu o fim de muitos recursos naturais, além de demonstrar sua angústia diante da ação devastadora do homem sobre o meio ambiente. Contudo, a crise ambiental teve seu impulso somente a partir das décadas de 1950/ 1960 (DIAS, 2004).

A Educação Ambiental (EA) teve seus pressupostos teóricos norteadores assumidos e ratificados ao longo da década de 1970, (DIAS, 2004; ALMEIDA e OLIVEIRA, 2007; BERNARDES e PRIETO, 2010) e desde essa época vem se consolidando como prática educacional que perpassa todas as áreas do conhecimento.

No atual cenário, Dias (2004) conceitua a EA como um conjunto de conteúdos e práticas ambientais orientadas para a resolução dos problemas concretos do ambiente, por meio do enfoque interdisciplinar e de uma participação ativa e responsável de cada indivíduo e da comunidade. Desta forma, não cabe mais uma visão reducionista do conceito de EA, na qual são privilegiadas apenas questões relativas ao meio ambiente, restringindo suas atividades ao ensino da ecologia.

Assim, é importante que os problemas ambientais da comunidade sejam analisados e que o aluno perceba que faz parte deste contexto, cabendo à EA levá-lo a compreender a estreita interação entre meio ambiente equilibrado e qualidade de vida do homem, além de mostrar que ela não se limita aos aspectos ecológicos, mas incorpora em seus objetivos os aspectos socioeconômicos, éticos e políticos. É essencial que a EA leve à prática da reflexão, construindo o conceito de autonomia e ampliando a ideia de cidadania nos alunos. Por estes motivos, a temática ambiental ainda encontra resistências em alguns países e segmentos da sociedade. Leff (2002), ao analisar a problemática ambiental, coloca que a mesma exige uma integração de saberes e aproximações sistêmicas, holísticas e interdisciplinares que, se limitadas à reorganização do saber disponível, são insuficientes para satisfazer a demanda de conhecimentos necessários para se trabalhar esta temática, demandando novos conhecimentos teóricos e práticos para sua compreensão e resolução.

A Constituição Brasileira de 1988 em seu artigo $225^{\circ}$ afirma que "Todos têm direito ao meio ambiente ecologicamente equilibrado, bem de uso comum do povo e essencial à sadia qualidade de vida, impondo-se ao Poder Público e à coletividade o dever de defendê-lo e preservá-lo para as presentes e futuras gerações” (BRASIL, 1988). Contudo, Santos (2000) destaca que, no Brasil, mesmo constando na Constituição Federal que a promoção da EA deve ser em todos os níveis de ensino, pouco estava sendo feito no contexto educativo para a sua implantação de forma satisfatória e eficaz.

Diante deste fato, fez-se necessário criar outros mecanismos que possibilitassem o avanço da EA no contexto educacional sendo então promulgada a Lei 9.795/99, que dispõe sobre a EA e que instituiu a Política Nacional de Educação Ambiental, apresentando-a como um componente essencial da educação brasileira e buscando a construção de habilidades e competências, valores e conhecimentos para a preservação do ambiente. A partir desta lei, a EA passa a ser vista e entendida como um processo e não como um fim em si mesmo, devendo ser desenvolvida como uma prática educativa integrada, contínua e permanente em todas as modalidades e níveis do ensino formal e não como uma disciplina incluída nos currículos escolares, mas através do viés interdisciplinar, haja vista a complexidade das questões ambientais.

Outra tentativa de enfatizar a EA como prática interdisciplinar, foi a inclusão da dimensão ambiental nos Parâmetros Curriculares Nacionais (PCNs). Cuja incorporação no currículo da educação básica buscou pôr fim a visão conteudista que ainda perdurava na educação brasileira. Para Souza (2004) a inserção da EA nos PCNs foi essencial, com sua visão integradora e transformadora, mas ainda falta uma indicação menos compartimentada dos conteúdos, o que poderia ocasionar em uma mudança das práticas pedagógicas. 
Entretanto, apesar destas iniciativas, ainda persiste a prática de uma EA que carece de maior compreensão quanto a sua aplicação interdisciplinar no processo educacional vigente. Diante disto, surge recentemente, uma nova tentativa de reforçar a legitimidade da EA com a homologação das Diretrizes Curriculares Nacionais para a Educação Ambiental (DCNEA) indicando que as Diretrizes Curriculares Nacionais para a Educação Básica em todos os níveis e modalidades reconhecem a relevância e a obrigatoriedade da EA (BRASIL, 2012) e reforçando o enfoque interdisciplinar, presente na Lei 9795/99:

Art. $8^{\circ}$ - A Educação Ambiental, respeitando a autonomia da dinâmica escolar e acadêmica, deve ser desenvolvida como uma prática educativa integrada e interdisciplinar, contínua e permanente em todas as fases, etapas, níveis e modalidades, não devendo, como regra, ser implantada como disciplina ou componente curricular específico (Ibid, p.3).

Inserindo-se neste contexto, este estudo debruça-se sobre uma investigação em um documento educacional brasileiro - as DCNEA - visando analisar como a EA é sugerida e apresentada para o seu desenvolvimento pelos docentes e instituições de ensino.

\section{METODOLOGIA}

Para o estudo do tema proposto, foi realizada uma pesquisa documental de cunho descritivo-explicativo. Guba e Lincoln (apud LÜDKE e ANDRÉ, 1989) destacam que os documentos constituem uma fonte rica e estável, daí sua importância, enquanto Dutra e Terrazan (2012, p. 173) ressaltam que "a pesquisa documental é parte integrante de qualquer pesquisa sistemática e precede ou acompanha os trabalhos de campo”.

O material utilizado para a análise, nesta pesquisa refere-se ao Parecer CNE/CO 14/2012 e à Resolução CNE/CP 02/2012 que constituem as DCNEA, atualmente vigentes como orientação para o trabalho com EA nos sistemas de ensino brasileiro.

A opção pelas DCNEA teve o propósito de verificar como está sendo sugerido, aos docentes e as instituições de ensino, o trabalho com a EA. Esta escolha deve-se ao fato de a mesma ter como objetivo orientar o planejamento curricular das escolas e dos sistemas de ensino, norteando seus currículos e conteúdos mínimos. Assim, as diretrizes asseguram a formação básica, com base na Lei de Diretrizes e Bases da Educação (LDB), definindo competências e diretrizes para a educação básica.

Tal documento foi analisado a luz da multirreferencialidade (ARDOINO, 1998). A abordagem multirreferencial pode ser entendida como uma pluralidade de olhares e linguagens para a apreensão da realidade estudada, e apesar de outras abordagens, como o marxismo (LEFF, 2002; DIEGUES, 2000) e a complexidade (MORIN, 2005), também trazerem contribuições importantes para o debate sobre a EA, optamos por contextualizar o estudo na multirreferencialidade. Isto porque, no campo da EA faz-se necessário a colaboração de diversos campos do saber, por intermédio da colaboração e participação de pesquisadores de diferentes formações acadêmicas e outros membros da sociedade, envolvidos com as questões ambientais. Além disso, a temática ambiental que segundo Burnham (2003) na sua própria essência não pode se contentar com abordagens disciplinares e científicas, haja vista que esta temática envolve aspectos enraizados nas culturas locais, nos saberes do cotidiano, entre outros, demanda diferentes referenciais que, articulados, podem vir a construir novos esquemas teóricometodológicos.

\section{RESULTADOS E DISCUSSÃO}

A grande importância da inserção da temática ambiental na prática educativa, atualmente é uma consequência dos complexos problemas ambientais planetários. Nas últimas décadas este tema vem ganhando espaço 
nas escolas e na sociedade como um todo. No Brasil a Constituição Federal de 1988, no inciso VI do $\S 1^{\circ}$ do artigo 225 já determinava que o Poder Público deveria promover a EA em todos os níveis de ensino. Entretanto, somente em junho de 2012 o Ministério da Educação do Brasil aprovou as Diretrizes Curriculares Nacionais para a Educação Ambiental.

Diretrizes são orientações para o pensamento e a ação. Neste sentido, as DCNEA trazem orientações explícitas de como deve ser pensada e conduzida a ação educacional na educação básica, em relação à EA. Neste contexto, percebe-se um destaque ao papel transformador e emancipatório da EA, diante do atual contexto nacional e mundial no qual a preocupação com o desequilíbrio ambiental, a extinção de algumas espécies, as mudanças climáticas locais e globais tornam-se latentes.

Nas últimas décadas a sociedade e o Poder Público tem mudado seu olhar em relação à EA levando o aluno a compreender a estreita interação entre meio ambiente equilibrado e qualidade de vida do homem, além de incorporar os aspectos multifacetários da questão ambiental. Neste sentido, ao ser feita a análise das DCNEA observa-se uma ênfase na visão complexa da questão ambiental. Segundo Morin (2005) o meio ambiente é um macrossistema complexo, cujos elementos estão interligados e inter-relacionados entre si. Por este motivo, o princípio do pensamento complexo contribui para a EA, haja vista que ele rompe com o paradigma pedagógico tradicional, que acaba por reduzir a EA a explicações simplificadas e desconexas, ao contrário pelo princípio do pensamento complexo o meio ambiente deve ser estudado de maneira integradora.

Analisando o documento selecionado neste trabalho, constata-se esta tendência expressa no mesmo:

Art. 13. I - desenvolver a compreensão integrada do meio ambiente em suas múltiplas e complexas relações para fomentar novas práticas sociais e de produção e consumo (BRASIL, 2012, p. 4);

Art. $1^{\circ}$ II - estimular a reflexão crítica e propositiva da inserção da Educação Ambiental na formulação, execução e avaliação dos projetos institucionais e pedagógicos das instituições de ensino, para que a concepção de Educação Ambiental como integrante do currículo supere a mera distribuição do tema pelos demais componentes (Ibid, p. 2);

Art. $4^{\circ}$ A Educação Ambiental é construída com responsabilidade cidadã, na reciprocidade das relações dos seres humanos entre si e com a natureza (Ibid, p. 2).

O documento também indica certa preocupação com as interações entre a sociedade, a cultura e o meio ambiente, sob o aspecto humanista democrático e participativo. Tais interações indicam uma preocupação com o futuro do planeta, que Bauman (apud SILVA et al, 2012) chamou de medo derivado, uma sensação de vulnerabilidade e insegurança diante dos problemas sociopolíticos, econômicos e culturais que nos acometem.

Associada a visão complexa da questão ambiental, as DCNEA reforçam o que, em 1999, a Lei 9.795 destacava em relação a este componente curricular. O documento aqui analisado ressalta a importância do desenvolvimento da EA como prática educativa integrada e interdisciplinar, contínua e permanente em todas as fases, níveis e modalidades, não devendo ser implantada como disciplina ou componente curricular específico (BRASIL, 2012).

Segundo Bernardes e Pietro (2010) nenhuma área de conhecimento consegue, isoladamente, tratar todas as questões ambientais. Assim, cabe à escola inserir esta temática ao projeto político-pedagógico da instituição e definir as ações e projetos a serem desenvolvidos. Então cabe destacar que, neste contexto, a interdisciplinaridade é voltada para uma abordagem epistemológica dos objetos de conhecimento, referindo-se, portanto, a uma relação entre as disciplinas; enquanto a transversalidade refere-se a dimensão da didática (metodológica), apontando uma transformação da prática pedagógica. 
Analisando as DCNEA constata-se esta tendência expressa no mesmo:

Art. 14. II - Abordagem curricular integrada e transversal, contínua e permanente em todas as áreas de conhecimento, componentes curriculares e atividades escolares e acadêmicas (BRASIL, 2012, p. 4).

Observa-se pelo fragmento citado uma orientação para o desenvolvimento da EA em suas múltiplas facetas. Neste sentido, faz-se extremamente necessário o resgate do planejamento participativo, cabendo à escola proporcionar aos seus alunos um ambiente favorável às discussões e reflexões com o intuito de contribuir para a formação de cidadãos conscientes de seu papel em relação ao meio ambiente. Desta forma, quando pensamos na temática ambiental é extremamente importante uma discussão entre docentes, escola e sociedade. Assim, observamos que a ausência de um projeto político-pedagógico dificulta a inserção de maneira eficaz desta temática na prática educativa.

Diante deste panorama, Almeida e Oliveira (2007) ressaltam a importância da atuação efetiva da escola no desenvolvimento da EA. Os autores afirmam que o desenvolvimento da EA é uma via de mão dupla na medida em que os resultados dessa atuação representam aspectos positivos para a escola.

Esta tendência foi constatada nas DCNEA, como destacado no trecho abaixo:

Art. 15. O compromisso da instituição educacional, o papel socioeducativo, ambiental, artístico, cultural e as questões de gênero, etnia, raça e diversidade que compõem as ações educativas, a organização e a gestão curricular são componentes integrantes dos projetos institucionais e pedagógicos da Educação Básica e da Educação Superior (BRASIL, 2012, p. 5);

$\S 1^{\circ}$ A proposta curricular é constitutiva do Projeto Político-Pedagógico (PPP) e dos Projetos e Planos de Cursos (PC) das instituições de Educação Básica, e dos Projetos Pedagógicos de Curso (PPC) e do Projeto Pedagógico (PP) constante do Plano de Desenvolvimento Institucional (PDI) das instituições de Educação Superior (Ibid, p. 5);

$\S 2^{\circ} \mathrm{O}$ planejamento dos currículos deve considerar os níveis dos cursos, as idades e especificidades das fases, etapas, modalidades e da diversidade sociocultural dos estudantes, bem como de suas comunidades de vida, dos biomas e dos territórios em que se situam as instituições educacionais (Ibid, p. 5).

Nos últimos tempos a preocupação com a intervenção do homem no meio ambiente tem crescido muito, obrigando a sociedade a repensar em suas atitudes e concepções. Neste contexto, Beck e colaboradores (2009) ressaltam que a diversidade de recursos naturais levou as sociedades ao errôneo entendimento de que estes seriam inesgotáveis. Desta forma, os desequilíbrios ambientais globais atualmente já demonstram que este erro de percepção requer a necessidade de mudança de comportamento e paradigmas no que se refere à visão econômica, empresarial, social e ecológica (LIRA e CÂNDIDO, 2008) e esta preocupação é constatada nas DCNEA como destacado abaixo:

Art. 17. II - O reconhecimento da importância dos aspectos constituintes e determinantes da dinâmica da natureza, contextualizando os conhecimentos a partir da paisagem, da bacia hidrográfica, do bioma, do clima, dos processos geológicos, das ações antrópicas e suas interações sociais e políticas, analisando os diferentes recortes territoriais, cujas riquezas e potencialidades, usos e problemas devem ser identificados e compreendidos segundo a gênese e a dinâmica da natureza e das alterações provocadas pela sociedade (BRASIL, 2012, p. 6).

Cabe ainda ressaltar que um dos papéis de destaque da EA é proporcionar ao aluno a compreensão da interação meio ambiente equilibrado/qualidade de vida do homem, além da importância do aprofundamento crítico-reflexivo, oriundo de estudos científicos e da perspectiva crítica dos desafios ambientais. Em relação 
a esta vertente Xavier e colaboradores (2012) ressaltam que tanto as práticas educativas ambientais, quanto o desenvolvimento sustentável são instrumentos promotores da qualidade de vida e da conservação ambiental.

Esta tendência é constatada no documento selecionado, como observamos abaixo:

III - aprofundamento do pensamento crítico-reflexivo mediante estudos científicos, socioeconômicos, políticos e históricos a partir da dimensão socioambiental, valorizando a participação, a cooperação, o senso de justiça e a responsabilidade da comunidade educacional em contraposição às relações de dominação e exploração presentes na realidade atual (BRASIL, 2012, p. 4).

IV - incentivo à pesquisa e à apropriação de instrumentos pedagógicos e metodológicos que aprimorem a prática discente e docente e a cidadania ambiental (Ibid, p. 4).

V - articulação na abordagem de uma perspectiva crítica e transformadora dos desafios ambientais a serem enfrentados pelas atuais e futuras gerações (Ibid, p. 4).

Diante deste cenário, a inserção da EA na escola vislumbra uma renovação na educação, “objetivando um ensino de qualidade no sentido de uma formação integral do aluno intencionado a contribuir para uma mudança de valores e atitudes, formando um sujeito ecológico capaz de identificar e problematizar questões socioambientais, agindo sobre elas” (CARVALHO, 2008, p. 156-157). Para tal, é necessário formar profissionais capacitados a esta nova realidade, docentes estes que possam discutir sobre EA de forma crítica.

Ao considerar as DCNEA observa-se esta preocupação expressa no documento:

Art. 19. Os órgãos normativos e executivos dos sistemas de ensino devem articular-se entre si e com as universidades e demais instituições formadoras de profissionais da educação, para que os cursos e programas de formação inicial e continuada de professores, gestores, coordenadores, especialistas e outros profissionais que atuam na Educação Básica e na Superior capacitem para o desenvolvimento didático-pedagógico da dimensão da Educação Ambiental na sua atuação escolar e acadêmica (BRASIL, 2012, p. 7);

$\S 1^{\circ}$ Os cursos de licenciatura, que qualificam para a docência na Educação Básica, e os cursos e programas de pós-graduação, qualificadores para a docência na Educação Superior, devem incluir formação com essa dimensão, com foco na metodologia integrada e interdisciplinar (Ibid, p. 7).

Neste sentido, Barroso e Taffarel (2004, p.236) ressaltam que “a EA no ensino superior enquanto área de referência científica, enquanto prática educativa cultural, enquanto disciplina curricular poderá trazer para repensar a teoria pedagógica e seu objeto”. Logo, cabe às universidades o papel de induzir o educando a desenvolver o senso crítico, sendo capaz de compreender e atuar na sociedade, proporcionando um conhecimento dialético e não meramente mecanicista. Assim, percebemos que no atual quadro de uma grave crise ambiental faz-se necessário um novo modelo de desenvolvimento e, sobretudo, uma nova formação de docentes e cidadãos visando a promoção de uma consciência ambiental sustentável.

Diante deste contexto, a EA deve ser considerada um processo educativo, já que ultrapassa o ambiente de ensino, e não somente uma disciplina a mais inserida no currículo escolar. Entretanto, o que se percebe na prática é que a maioria das ações didáticas voltadas para a EA são desenvolvidas de forma confusa e desarticulada, ficando a cargo de práticas pontuais de alguns docentes. Além disso, a abordagem usada ainda hoje na maioria das salas de aula é claramente naturalista, considerando o meio ambiente somente no viés biológico (SILVA, 2008).

Ainda em relação às DCNEA, o documento em questão ressalva que a inserção desta temática nas instituições de ensino de âmbito municipal e estadual ficaria a cargo dos Conselhos de Educação dos Estados, como observa-se no trecho abaixo: 
Art. 18. Os Conselhos de Educação dos Estados, do Distrito Federal e dos Municípios devem estabelecer as normas complementares que tornem efetiva a Educação Ambiental em todas as fases, etapas, modalidades e níveis de ensino sob sua jurisdição (BRASIL, 2012, p. 6).

Porém, na prática se observa um grande desconhecimento da legislação que sustenta as ações voltadas para a EA, por parte dos docentes da educação básica. O Poder Público que deveria assumir a responsabilidade em repassar tais orientações, ainda hoje não o faz, pois encontramos estados e municípios que não possuem normas complementares que favoreçam ações que promovam uma EA crítica-reflexiva, transformadora e emancipatória.

\section{CONSIDERAÇÕES FINAIS}

A partir deste estudo, constatou-se que as DCNEA estão baseadas em uma concepção de EA crítica, reflexiva e emancipatória, buscando um trabalho contínuo desta temática. Ao longo de todo o texto, percebe-se que a EA, é pretendida como processo permanente visando à conquista da cidadania e de um desenvolvimento sustentável. Observa-se também que o trabalho da temática ambiental procura incentivar os alunos a refletirem sobre os problemas locais e globais, agindo sobre os mesmos na busca de um novo paradigma na relação sociedade/ meio ambiente.

Se por um lado as DCNEA chamam a atenção dos educadores para a problemática ambiental levando-os a se autoavaliarem e questionarem suas posições e esforços para o seu desenvolvimento, por outro lado o documento não responde as dificuldades das escolas sem estrutura, sem materiais pedagógicos ou com projetos pedagógicos compartimentados em disciplinas estanques, o que dificulta a inserção desta temática na prática educativa de uma forma eficaz.

Além disso, apesar do documento incentivar a todo instante o desenvolvimento da EA na perspectiva interdisciplinar, o mesmo não atenta para o fato de que no Brasil, ainda hoje, encontramos uma educação compartimentada na qual as áreas de conhecimento pouco dialogam entre si e também com a realidade dos alunos.

É claro que indicar o caminho a ser trilhado no desenvolvimento da EA é importante, mas somente isso não garante a inserção desta temática na prática educativa. Tão importante quanto criar um documento que oriente os docentes para o desenvolvimento da temática ambiental é proporcionar, aos mesmos, condições para que o trabalho seja desenvolvido. A necessidade da capacitação permanente de professores, além, da melhoria das condições de trabalho são apenas alguns pontos a serem destacados neste processo. 


\section{REFERÊNCIAS}

ALMEIDA, M.P.Q; OLIVEIRA, C.I. Educação Ambiental: importância da atuação efetiva da escola e do desenvolvimento de programas nesta área. Revista Eletrônica de Mestrado em Educação Ambiental, v. 18, p. 12-24, 2007.

ARDOINO, J. Nota a Propósito das Relações entre a Abordagem Multirreferencial e a Análise Institucional. In: Barbosa J.G, org. Multirreferencialidade nas Ciências e na Educação. São Carlos, UFSCar, 1998.

BARROSO, G; TAFFAREL, C.N.Z. Didática do ensino superior: teoria pedagógica e crítica à organização do processo de trabalho pedagógico no ensino superior. Revista da Faced. Universidade Federal da Bahia. $n^{\circ} 8$, 2004.

BECK, C. G; ARAUJO, A. C.; CÂNDIDO, G. A. Problemática dos Resíduos Sólidos Urbanos do Município de João Pessoa: Aplicação do Modelo P-E-R. Qualit@s Revista Eletrônica, v. 8, n. 3, 2009.

BERNARDES, M. B. J.; PRIETO, E. C. Educação Ambiental: disciplina versus tema transversal. Revista Eletrônica Mestrado em Educação Ambiental, v. 4, p. 173-185, 2010.

BRASIL. Constituição da República federativa do Brasil: promulgada em 5 de outubro de 1988. Brasília, DF, Senado, 1988.

. Lei n. 9.795, de 27 de abril de 1999. Estabelece a política nacional de educação ambiental. Brasília, 1999.

_. Resolução nº2, de 15 de junho de 2012. Estabelece as Diretrizes Curriculares Nacionais para a Educação Ambiental. Diário Oficial da União. Brasília: DOU, 2012.

BURNHAM, T. F.; Pesquisa multirreferencial em educação ambiental: bases sócio-culturais-políticoepistemológicas. Texto apresentado na Mesa-redonda Fundamentos teórico-metodológicos das Pesquisas em EA: a articulação necessária, do II Encontro de Pesquisa em Educação Ambiental, realizado no período de 27 a 30 de julho de 2003, na UFSCar. Disponível em: http://www.revistas.usp.br/pea/article/view/30010/31897. Acesso em: 27 de outubro de 2014.

CARVALHO, I. C. de M., Educação ambiental: a formação do sujeito ecológico. $4^{\mathrm{a}}$ edição. São Paulo: Cortez, 2008.

DIAS, G. F. Educação Ambiental: princípios e práticas. 9a edição. São Paulo: Gaia, 2004.

DIEGUES, A. C. S. O mito moderno da natureza intocada. 3. ed. São Paulo: Hucitec/USP, 2000.

DUTRA, F.; TERRAZZAN, E. A. E. Reflexos das normativas legais sobre formação de professores da educação básica em configurações curriculares de cursos de licenciatura em química e formação da identidade profissional docente. Ensaio Pesquisa em Educação em Ciências, v. 14, n. 1, p. 169-180, 2012.

LEFF, E. Epistemologia ambiental. 2a edição. São Paulo: Cortez, 2002.

LIRA, W. S.; CÂNDIDO, G. A. Análise dos Modelos de Indicadores no Contexto do Desenvolvimento Sustentável. Revista Perspectivas Contemporâneas, v. 3, n. 1, p. 31-45, 2008.

LUDKE, M; ANDRE, M. E. D. A. Pesquisa em educação: abordagens qualitativa. São Paulo: EPU, 1986.

MORIN, E. Os sete saberes necessários à educação do futuro. Brasília: Cortez, UNESCO, 2005. 
SANTOS, A. S. R dos. Educação Ambiental e o poder público. Disponível em: http://www.aultimaarcadenoe. com.br/educacao-ambiental-3, 2000. Acesso 20 de março de 2014.

SILVA, A. S. Educação Ambiental: aspectos teóricos-conceituais, legais e metodológicos. Educação em Destaque, v. 1, n. 2, p. 45-61, 2008.

SILVA, P. O; VIEIRA, V. T; HENNING, P. C. Educação ambiental e discursos midiáticos: gerenciando modos de vida contemporâneos. In: IX ANPED SUL - SEMINÁRIO DE PESQUISA EM EDUCAÇÃO DA REGIÃO SUL, 9, 2012, Caxias do Sul. Anais do IX ANPED SUL 2012.

SOUZA, D. A. A Relação da Criança com o Meio Ambiente: A Educação Ambiental nos Contextos Escolares. 2004. 143 f. Dissertação (Mestrado em Educação) - Instituto superior de Estudos Pedagógicos, Rio de Janeiro, 2004.

XAVIER, T. R.; SANTOS, R. A; FERREIRA, M. G. M.; WITTMANN, M. L.; SOUZA, R. A. R. Educação ambiental como mecanismo propulsor da qualidade de vida e preservação do meio ambiente: um mapeamento das práticas educativas ambientais em empresas no município de Ouro Preto/MG. Sinapse Múltipla, v. 1, n. 1, p. 15-30, 2012. 